\title{
EDITORIAL
}

\section{A fisiatria na formação do médico generalista}

Linamara Rizzo Battistella

A resolução do problema do incapacitado, isto é, o tratamento de reabilitação, é um processo de grande complexidade, exigindo na maior parte dos casos a ação de uma Equipe Multidisciplinar, que trabalha com objetivos comuns, mesmo atuando em áreas diferentes: com o paciente diretamente, sua família, sua comunidade.

É notório o fato que a fragmentação do tratamento fisiátrico, em qualquer fase de sua execução, conduz ao insucesso, pois são inúmeras as variáveis em jogo e nunca um único elemento será capaz de fornecer todos os subsídios necessários ao paciente em questão.

Convém salientar também, que o desenvolvimento do potencial máximo de um paciente deficiente é um ato que envolve a saúde do indivíduo e saúde é sempre uma responsabilidade médica, cabendo ao médico o papel de principal mentor do tratamento de reabilitação. Os demais elementos de Equipe devem ser acionados, de acordo com as necessidades e peculiaridades de cada paciente, procurando sua melhora funcional, o equilíbrio das funções orgânicas, ajuste social e profissionalização.

Os países desenvolvidos, baseados nesses fatos criaram grandes Centros de Reabilitação com ênfase, nos vários tipos de doenças incapacitantes, onde porém, se preserva a idéia de reabilitação = processo terapêutico, executado por todos os elementos da Equipe, mas sempre sob responsabilidade médica.

Disso tudo, vale dizer, originou-se a especialidade médica conhecida no nosso meio como Fisiatria ou Medicina Física e de Reabilitação*, já reconhecida pelo Conselho Federal de Medicina , Associação Médica Brasileira e Comissão Nacional de Residência Médica, que agrega em torno de si os profissionais médicos que se interessam pelo aspecto global da reabilitação. O médico fisiatra deve conhecer profundamente as doenças incapacitantes, assim como os aspectos psicossociais do doente incapacitado, para que possa exercer com competência a sua função: diagnóstico e prescrição do tratamento das doenças incapacitantes, em qualquer fase do processo patológico.

A realidade nacional, quando se fala em reabilitação, apresenta um aspecto de fundamental importância que é o paradoxo entre a existência de cursos de aprimoramento e especialização à nível de Residência e Estágios e a falta de informação sobre o tema na formação do médico generalista, criando com isso a falsa impressão que todos os procedimentos desta área são competência exclusiva do médico especialista.

O curso de Medicina de Reabilitação corresponde à formação teórico-prática que o médico generalista necessita e deve ter no que 
diz respeito às necessidades mais freqüentes, e dos procedimentos que a ciência médica, tem na atualidade, para prevenção, tratamento e recuperação.

Medicina Física e Reabilitação (Fisiatria), se define como ramo da Medicina que:

a.) - contribui para a prevenção da incapacitante física e mental.

b.) - detecta precocemente, avalia e diagnostica em forma integral, todos os tipos de processos incapacitantes.

c.) - prescreve, dirige, supervisiona e avalia os programas e procedimentos adequados para adaptar ou readaptar a pessoa incapacitada, por meio da restauração ou restabelecimento do movimento, das funções da comunicação humana e da eficiência psicológica, social e vocacional, fazendo uso dos recursos médicos, da família e da comunidade.

d.) - investiga as causas e mecanismos da incapacidade em todas suas formas e as respostas dos tecidos, órgãos e sistemas às ações terapêuticas desenvolvidas nesta área do conhecimento (Terapeutica Medicamentosa e não Medicamentosa).

As últimas décadas se caracterizaram por um avanço acelerado das ciências e tecnologia, além de uma série de circunstâncias que propiciaram aumento do número de pessoas com limitações físicas, sensoriais ou mentais, razão pela qual o médico generalista deve dispor dos conhecimentos, habilidades e destrezas necessárias que permitam resolver os problemas. Devemos adequar nosso sistema de atenção médica, ante situações relevantes em nosso país, tais como:

- O fenômeno de urbanização que fomenta, condições desfavoráveis com aumento dos riscos para a saúde, em relação com a decomposição e desorganização das massas urbanas, antes desconhecidas ou de pouca importância.
- As mudanças etárias suscitadas no fenômeno demográfico, pela diminuição da taxa bruta de natalidade que leva a uma diminuição dos grupos menores de 15 anos e aumento dos grupos maiores de 15 anos (dados mundiais).

A mortalidade infantil apresentou importante diminuição com base na melhoria dos Serviços de Saúde e em especial pelo aumento das campanhas de prevenção orientadas para o Grupo Materno Infantil.

Como conseqüência do anterior, a esperança de vida da população aumentou, sendo atualmente 70 anos aproximadamente.

- A queda das condições de saúde da população adulta, evidenciado pelo aumento na morbimortalidade por câncer, enfermidades do aparelho respiratório e enfermidades crônicas em geral.

- Há um aumento inusitado de morbidade por violência e acidentalidade, derivado de situações complexas de ordem social, cultural, político e econômica.

- Segundo os poucos estudos estatísticos existentes, cerca de $15 \%$ de nossa população padece algum tipo de deficiência.

- Há um total desconhecimento do médico generalista da problemática nacional quanto a invalidez; desconhecimento do impacto e das alterações que se produz na saúde do indivíduo no núcleo da família e na comunidade.

O médico atual não está preparado para trabalhar as conseqüências da enfermidade, do traumatismo e do acidente. Não lhe é ensinado sobre a prevenção e tratamento das seqüelas das enfermidades crônicas não transmissíveis.

A orientação dos especialistas principalmente nas áreas cirúrgicas é para resultados imediatistas, o que não for resolvido por cirurgia e esquecido, negligênciado para um segundo plano, podendo ser causa de incapacidades secundárias. 